\title{
Neurobehavioral and Immunological Consequences of Prenatal Immune Activation in Rats. Influence of Antipsychotics
}

\author{
Eva Romero*,', Carine Ali ${ }^{1,3}$, Eduardo Molina-Holgado ${ }^{1,4}$, Bernardo Castellano ${ }^{2}$, Carmen Guaza' and \\ José Borrell'
}

'Cajal Institute, Spanish Council for Scientific Research (CSIC), Avda Doctor Arce, Madrid, Spain; ${ }^{2}$ Unit of Histology, Faculty of Medicine,

Torre M-5 Autonomous University of Barcelona, Bellaterra, Spain

\begin{abstract}
Increasing evidence suggests that pre- or perinatal events that influence the immune system contribute to the development of behavioral or neuropsychiatric disorders. For instance, exposure of pregnant rats to the bacterial endotoxin lipopolysaccharide (LPS) disrupts sensorimotor information processing, as assessed by the prepulse inhibition test (PPI), and also the immune function in adult offspring, which might be of particular relevance as regards schizophrenia. However, the consequences of maternal LPS exposure during pregnancy on synaptic functioning in adult offspring and, more importantly, the therapeutic opportunity to re-establish PPI and immune function have still to be demonstrated. In this work, we analyzed the consequences of prenatal LPS exposure on dopaminergic neurotransmission and presynaptic markers in adult brain areas related to PPI circuitry. In addition, we tested whether oral treatment with the typical antipsychotic drug haloperidol (HAL) could reinstate PPI performances and cytokine serum levels in six-month-old male rats with prenatal LPS exposure. Both sensory information processing deficits and immune anomalies induced by prenatal exposure to LPS were accompanied by changes in dopaminergic neurotransmission and synaptophysin expression. It is important to note that PPI disruption and serum increases in cytokines induced by prenatal LPS exposure were both reversed by HAL. Taken together, these results demonstrate the critical influence of prenatal immune events on the functioning of adult nervous and immune systems, in association with the putative role of the immune system in the development of behavior relevant to schizophrenia.
\end{abstract}

Neuropsychopharmacology (2007) 32, 179 I-1804; doi: 10.1038/s.npp. I 30 I292; published online 20 December 2006

Keywords: LPS; schizophrenia; prepulse inhibition; cytokine; dopamine; neurodevelopment

\section{INTRODUCTION}

Events occurring within the intrauterine or perinatal environment may have significant consequences for the development and function of physiological systems throughout an individual's lifespan. For instance, there is evidence that pre- or perinatal events that influence the immune system contribute to the development of behavioral or neuropsychiatric disorders, including schizophrenia, autism, and cerebral palsy (Borrell et al, 2002; Hornig et al, 1999; Shi et al, 2003). Early exposure to infectious agents may influence reactivity to stress, immune regula-

\footnotetext{
*Correspondence: Dr E Romero. Current address: Molecular Biology of the Cell, Ecole Normale Supérieure de Lyon, 46 allée d'Italie, Lyon cedex 07, 69364, France, Tel: + 334727286 I5, Fax: + 3347272 80 80, E-mail: Eva.Romero@ens-lyon.fr

${ }^{3}$ Current address: INSERM-Avenir 'tPA in the working brain', GIP CYCERON, Bd Becquerel, BP 5229, I 4074 Caen cedex, France.

${ }^{4}$ Current address: National Hospital of Paraplegia (SESCAM) Finca La Peraleda s/n, 4507| Toledo, Spain.

Received 6 July 2006; revised I I October 2006; accepted 2 November 2006
}

tion, and susceptibility to disease later in life (Boisse et al, 2004; Hodgson et al, 2001; Shanks et al, 2000).

Cytoarchitectural and morphological brain changes observed in schizophrenia, together with epidemiological data, are consistent with a pre/perinatal origin suggesting that neurodevelopmental disturbances contribute to the etiology of at least some cases of this disorder (Rapoport et al, 2005). This is supported by brain imaging and post-mortem neuropathological findings in brains from schizophrenic individuals, indicating a failure in some developmental processes such as neurogenesis, neuronal proliferation, neural differentiation, migration, and synaptogenesis (Rapoport et al, 2005).

Maternal exposure, during pregnancy, to influenza (Brown et al, 2004a; Mednick et al, 1988), poliovirus (Suvisaari et al, 1999), rubella, measles, varicella-zoster (Brown and Susser, 2002), retrovirus (Yolken et al, 2000), and bacterial agents (O'Callaghan et al, 1994), has been associated with an increased risk for schizophrenia in the offspring. This suggests that a maternal immune response, common to various infectious agents, could influence fetal brain development and, consequently, lead to schizophrenia. Interestingly, maternal serum levels of tumor necrosis 
factor- $\alpha$ (TNF- $\alpha)$ (Buka et $a l, 2001)$ or interleukin (IL)-8 (Brown et al, 2004b) are elevated in mothers of patients with schizophrenia. In addition, an in vitro study shows that the inflammatory cytokines TNF- $\alpha$, IL- $1 \beta$, and IL- 6 can inhibit the development of dendrites in embryonic cortical neurons, consistent with the neuropathology of schizophrenia (Gilmore et al, 2004). In rats, neonatal administration of proinflammatory cytokines (Tohmi et al, 2004) or leukemia inhibitory factors (Watanabe et al, 2004) induce future psychobehavioral and/or cognitive impairments. Thus, it is likely that the maternal immune response, particularly involving the proinflammatory cytokines, interferes with normal fetal brain development and that maternal infections during pregnancy are potential risk factors for schizophrenia (Gilmore et al, 2004; Nawa and Takei, 2006).

One marker associated with patients and individuals atrisk for schizophrenia is a deficient prepulse inhibition (PPI) of the startle reflex (Swerdlow et al, 2006). PPI is a well-established sensorimotor gating paradigm and refers to the normal reduction in startle that occurs when the startling stimulus is preceded $30-300 \mathrm{~ms}$ by a weak prestimulus (Graham, 1975). Patients with schizophrenia show less PPI (Braff et al, 1978; Kumari et al, 1999; Weike et al, 2000), and it is partially restored by sustained treatment with antipsychotics (Kumari et al, 1999; Weike et al, 2000). PPI deficits have been widely used in animal studies to explore the central mechanisms that may be involved in schizophrenia (Swerdlow and Geyer, 1998) and drug-induced disruption of PPI in animals is considered as being among the most useful predictive preclinical model of antipsychotic potential (Geyer et al, 2001). In rats, the schizophrenic-like PPI deficit can be induced by pharmacological or surgical manipulations targeting mainly the cortico-meso-limbic circuitry (Lipska, 2004; Schwabe and Koch, 2004). However, PPI deficits in schizophrenia, and other neuropsychiatric disorders, are mainly innate, probably as a result of genetic and (early) environmental influences (Lewis and Levitt, 2002). Therefore, it is of great interest to develop non-pharmacological paradigms of PPI deficit thus mimicking more closely the clinical situation and, for this reason, animal neurodevelopmental models of schizophrenia have received a lot of attention.

Although maternal infection during pregnancy has been identified as a risk factor for schizophrenia and other neurodevelopmental disorders (Brown, 2006), little is known about the mechanisms through which this environmental impact occurs. In this respect, recent work by our research group, and others, has involved an attempt to model the long-term consequences of maternal infection during pregnancy on subsequent offspring behavior. These models include exposure to lipopolysaccharide (LPS), a bacterial cell wall endotoxin (Borrell et al, 2002; Fortier et al, 2004), infection with human influenza virus and exposure to polyriboinosinic-polyribocytidilic acid (poly I: C), which mimics viral RNA (Shi et al, 2003; Zuckerman et al, 2003). The converging evidence from these studies suggests a causal relationship between activation of the immune system during pregnancy and altered behavior in the offspring relevant to schizophrenia.

Systemic administration of LPS is a widely accepted model for emulating immune activation and it is known to release peripheral immunoregulatory cytokines (Wright et $a l, 1990)$ and also to stimulate cytokine expression in the central nervous system (CNS) (Quan et al, 1999). Maternal LPS exposure increases cytokine expression in the maternal blood, placenta, and amniotic fluid of rodents (Gayle et al, 2004; Urakubo et al, 2001), alters brain-derived neurotrophic factor and nerve growth factor expression in the developing brain and maternal-fetal unit (Gilmore et al, 2003) and causes a long-term decrease in TNF- $\alpha$ in the neonatal brain (Gilmore et al, 2005). It has been suggested that the effects of maternal LPS exposure on the developing fetal brain may be mediated by cytokine induction in the maternal circulation or placenta (Ashdown et al, 2006). There is an increasing body of evidence that cytokine abnormalities are involved in the pathophysiology of schizophrenia and that antipsychotic treatment influences cytokine levels (Drzyzga et al, 2006).

We have previously reported that peripheral administration of LPS to pregnant rats disrupts PPI and increases the level of serum cytokines in adult offspring (Borrell et al, 2002). In the present study, using the prenatal immune challenge paradigm, we have performed two sets of experiments in six-month-old male rats. In the first set of experiments we assessed the effects of prenatal LPS exposure on dopaminergic function, as disrupted PPI is related to hyperdopaminergic function (Geyer et al, 2001) and there is a widely accepted role of subcortical dopaminergic hyperfunction in schizophrenia (Deutch, 1992). We measured the ex vivo tissue levels of dopamine (DA), and its metabolites, 3,4-dihydroxyphenylacetic acid (DOPAC), and homovanillic acid (HVA), in the nucleus accumbens (NAC) and the striatum, two brain regions involved in sensorimotor gating processing (Swerdlow and Geyer, 1998). In addition, we analyzed the expression profile of DA- and cAMP-regulated phosphoprotein (DARPP-32), a mediator of DA effects (Fienberg et al, 1998), in brain areas (the frontal cortex, hippocampus, and amygdala) considered as being the neural substrates of schizophrenia (Lewis and Lieberman, 2000). Because accumulating evidence suggests that schizophrenia is largely a disorder of neural connectivity (Honer, 1999; Thompson et al, 2003), the present study was also undertaken to determine whether or not maternal LPS administration leads to presynaptic protein expression abnormalities. We examined the expression profile of two presynaptic proteins that have been extensively linked to schizophrenia, synaptophysin, and growth-associated protein 43 (GAP-43) (Chambers et al, 2005; Halim et al, 2003), in the frontal cortex, the hippocampus, and the amygdala. In the second set of experiments, we tested the ability of oral treatment with the antipsychotic drug haloperidol (HAL) to restore the PPI and cytokine serum levels altered by prenatal LPS exposure. We also measured the long-term effects of HAL on PPI and cytokine serum levels.

\section{MATERIALS AND METHODS}

\section{Animals}

All procedures involving animals and their care complied with national and international laws and policies. Wistar rats from our in-house colony were used. They were kept 
under standard conditions $\left(22 \pm 2^{\circ} \mathrm{C}, 12: 12 \mathrm{~h}\right.$ light/dark cycle; lights on at 0700) and received food and water ad libitum.

\section{Prenatal Administration of LPS}

Vaginal smears were taken daily from breeder females and, when found to be in estrus, females were placed with males. Pregnancy was determined the next morning by the presence of sperm in the vaginal smear (= day 0 of pregnancy) and each pregnant dam was housed individually. LPS from Escherichia coli (Sigma L-3755 Serotype 026:B6) was subcutaneously administered to pregnant rats $(n=16)$ at a dose of $2 \mathrm{mg} / \mathrm{kg}$. LPS was dissolved in saline and injected in a volume of $1.5 \mathrm{ml} / \mathrm{kg}$ between 0900 and 1100 Injections were given daily from day 1 to 21 of pregnancy. If a dam was not delivered on day 22 before 1100 an additional injection was administered. The control group consisted of pregnant rats $(n=11)$ submitted to the same treatment schedule but with saline. After delivering, the dams were allowed to rear their offspring until weaning. At 4 days old the offspring were sexed and counted. No differences in litter size were observed between LPS- and saline-treated rats. At 21 days old, the offspring were weaned and caged in selected groups of three animals of the same prenatal treatment and the same sex. Each group of animals (prenatally LPS-exposed rats and controls) were selected in a semirandom way with the restriction that a maximum of one offspring of each pregnant rat was selected in order to minimize the potential complication of a litter effect (Zorrilla, 1997). In the present study only male offspring obtained from pregnant rats treated with LPS or saline were used. Animals chosen to study the effects of antipsychotic treatment remained caged in groups of three throughout the treatment.

\section{Administration of HAL}

HAL was administered in the drinking water during 14 consecutive days. The dose of HAL was based on previous dosing strategies in rats that had been extrapolated from human clinical dosages (See and Ellison, 1990). HAL (Sigma, H-1512) was dissolved in a few drops of acetic acid and diluted at $0.05 \mathrm{mg} / \mathrm{ml}(\mathrm{pH}$ 5.0-5.5). Solutions were prepared twice a week and covered with aluminum foil to prevent photo-oxydation. The daily dosage, calculated from drinking water intake, was approximately $1.2 \mathrm{mg} / \mathrm{kg}$. Vehicle (VEH) treatment consisted of water adjusted with diluted acetic acid to match the $\mathrm{pH}$ of the drug solution.

\section{PPI Testing}

All male rats were tested for their acoustic startle when reaching the age of 6 months. Concerning the PPI assays, two independent experiments were performed. In experiment 1,30 offspring obtained from pregnant rats injected with LPS or saline (16 LPS and 14 controls) were tested for PPI. Twenty-four hours after the PPI testing, animals were decapitated with the use of a guillotine. Brains were quickly removed, frozen in dry ice, and stored at $-80^{\circ} \mathrm{C}$ for further neurochemical assays and trunk blood was collected for cytokine assays. In experiment 2 , rats prenatally exposed to
LPS or saline were tested for PPI 2 weeks before being submitted to an oral treatment with HAL or VEH for 14 days ( $n=12 \pm 2$ animals for each experimental group: control + VEH, control + HAL, LPS + VEH, and LPS + HAL). These animals were tested for the PPI of acoustic startle response on the first and the last days of treatment. After PPI testing, HAL was removed from the control + HAL and the LPS + HAL groups and these animals were tested again for PPI 1 day or 2 weeks later. Animals were killed $24 \mathrm{~h}$ after the PPI testing and trunk blood was collected for cytokine assays. In order to minimize the number of animals used in the present study, rats from control $+\mathrm{VEH}$ and LPS + VEH groups were submitted to a treatment with HAL for 14 days and then killed for further cytokine assays.

The startle device consisted of a non-restrictive Plexiglas cage $(28 \times 15 \times 17 \mathrm{~cm})$, which encloses the sensor's platform but does not touch it. If the animal moves up or down, a transient force is developed on the platform. This transient force is measured at its peak, being the equivalent of the amplitude of the startle response. Startle movements of the rat were transduced by an accelerometer (Cibertec SA, Madrid, Spain) and the signal was sampled and digitized by a microcomputer, which also served to present stimuli and to record data. The startle device was located in a soundattenuating chamber $(90 \times 55 \times 60 \mathrm{~cm})$ constantly illuminated (10 W lamp) and equipped with a loudspeaker, located in the top of the chamber, which constantly provided a $46 \mathrm{~dB}[\mathrm{~A}]$ background white noise. Two $28 \mathrm{~cm}$ loudspeakers (Cibertec SA, Madrid, Spain), located $15 \mathrm{~cm}$ from both sides of the Plexiglas cage, produced the various acoustic stimuli. These speakers were connected to an audio-amplifier (Cibertec SA, Madrid, Spain), which, in turn, was connected to one noise generator (2001 Function Generator, Columbus, $\mathrm{OH}$, USA) providing the acoustic startle stimulus and to a second noise generator (BF-1 Retex, Madrid, Spain), which provided the auditory signal corresponding to the auditory prepulses. The acoustic startle stimulus was a pure tone pulse of $20 \mathrm{kHz}, 100 \mathrm{~ms}$ duration ( $10 \mathrm{~ms}$ rise and decay times), and of $100 \mathrm{~dB}[\mathrm{~A}]$ intensity. The auditory prepulse stimulus was a pure tone pulse of $250 \mathrm{~Hz}, 50 \mathrm{~ms}$ duration ( $5 \mathrm{~ms}$ rise and decay times) at an intensity of $56 \mathrm{~dB}[\mathrm{~A}](10 \mathrm{~dB}$ above the background noise), delivered $100 \mathrm{~ms}$ before the acoustic startle stimulus. Sound measurements were made within the Plexiglas cage using a sound level meter (Brüel and Kjaer, Darmstad, Germany). The light stimulus, corresponding to the visual prepulse stimulus, was produced by a xenon lamp located $30 \mathrm{~cm}$ above the top of the Plexiglas cage. This lamp was connected to a photic stimulator (FF-40, Cibertec SA, Madrid, Spain). The visual prepulse stimuli consisted of a photic stimulus of $20 \mathrm{~ms}$ duration, with near instantaneous rise and decay times delivered $100 \mathrm{~ms}$ before the acoustic startle stimulus.

After an initial 5-min acclimation period, 30 startle eliciting stimuli alone $(100 \mathrm{~dB}[\mathrm{~A}])$ were presented. These initial startle pulses lead to some adaptation, which reduces variability and stabilizes the baseline startle amplitude (Campeau and Davis, 1995), but they were not used in the estimation of PPI. In experiment $1,30 \mathrm{~s}$ following the last initial startle stimulus, 45 additional $100 \mathrm{~dB}[\mathrm{~A}]$ startle stimuli were presented, consisting of 15 startle stimuli alone (pulse alone trials), 15 startle stimuli occurring after 
the auditory prepulse (auditory trials), and 15 startle stimuli occurring after the visual prepulse (visual trials). In experiment 2, the stimuli sequence consisted of 17 pulse alone trials, 12 auditory trials, and 12 visual trials. For both experiments the startle stimuli were presented at a fixed interstimulus interval of $20 \mathrm{~s}$ and the occurrence of each trial type was semirandom with the restriction that each trial type had to occur in every three trial block. The amount of PPI is expressed as the percentage decrease in the amplitude of the startle response caused by presentation of the prepulse ( $\% \mathrm{PPI}$ ), according to the formula: (100-(startle amplitude on prepulse trials/startle amplitude on pulse alone trials) $\times 100)$.

\section{Tissue Dissections}

On a cold plate, brains were sliced into $1-2 \mathrm{~mm}$ thick coronal sections and small tissue samples were microdissected by hand under a binocular microscope (Paxinos and Watson, 1997). The NAC was sampled at the level of the rostral neostriatum and comprised the intranuclear portion of the anterior commissure between interaural (IA) planes 11.2 and $10.2 \mathrm{~mm}$. The neostriatum included the caudate nucleus and putamen rostral to the anterior commissure between IA 10.7 and $9.7 \mathrm{~mm}$. The frontal cortex included the primary cortex from 12.2 to $11.2 \mathrm{~mm}$. The hippocampus was excised from the midbrain and the overlying cerebral cortex, between IA 6.2 and $4.2 \mathrm{~mm}$. The amygdala contained the basal, medial, anterior, and posterior amygdalar nuclei between IA 6.7 and $5.2 \mathrm{~mm}$.

\section{Biochemical Analysis of DA, DOPAC and HVA}

Samples from the NAC and neostriatum were homogenized in $500 \mu \mathrm{l}$ of a mobile phase of $0.1 \mathrm{M} \mathrm{NaH} \mathrm{NO}_{4}, 1 \mathrm{mM}$ $\mathrm{Na}_{2}$ EDTA, $1.66 \mathrm{mM}$ Octane-1-sulfonic acid sodium salt and centrifuged at $12000 \mathrm{~g}$ for $15 \mathrm{~min}$ at $4^{\circ} \mathrm{C}$. Pellets were resuspended in $1 \mathrm{M} \mathrm{NaOH}$ for protein assay (Bio-Rad, Hercules, CA) and supernatants were analyzed by reversephase high-performance liquid chromatography (HPLC) with electrochemical detection. In brief, samples were injected into a $5-\mu \mathrm{m}$ particle-size analytical HPLC column $(200 \times 4.6 \mathrm{~mm}$; Spherisorb ODS2, from SYMTA, Madrid, Spain) and the detector was an ESA Coulochem Model 5100A (ESA Analytical, Chelmsford, MA) with a Model 5011 dual analytical cell and a Model 5021 conditioning cell. The mobile phase was prepared as mentioned above but containing $7 \%$ methanol (vol/vol). The flow rate was set at $1 \mathrm{ml} / \mathrm{min}$, and the electrode potentials of detector 1 , detector 2 and the conditioning cell were $+0.08 \mathrm{~V},+0.45 \mathrm{~V}$, and $-0.30 \mathrm{~V}$, respectively. The peak areas generated from the compounds were recorded and quantified by comparison with external standards containing $25 \mathrm{ng} / \mathrm{ml}$ of DA and DOPAC, and $50 \mathrm{ng} / \mathrm{ml}$ of HVA. The standard curves were injected before and after every chromatographic run. Peak areas and retention times showed a very good reproducibility with coefficients of variation below $5 \%$.

\section{Immunoblotting}

Samples from the frontal cortex, the hippocampus and the amygdala were homogenized in $500 \mu \mathrm{l}$ of ice-cold $10 \mathrm{mM}$
HEPES pH 7.6, containing 1\% Triton X-100, 1 mM EDTA, $1 \mathrm{mM}$ EGTA, $1 \mathrm{mM}$ sodium orthovanadate, $2 \mathrm{mM} \mathrm{NaF}$, $5 \mathrm{mM}$ DTT, and a mixture of protease inhibitors (Complete $^{\mathrm{TM}}$, Roche Applied Science, Barcelona, Spain). The homogenates were centrifuged at $12000 \mathrm{~g}$ for $15 \mathrm{~min}$, at $4^{\circ} \mathrm{C}$, and the supernatants were removed for further analysis. Protein concentration was determined with Bradford reagent (Bio-Rad) using bovine serum albumin as a standard. Tissue lysates were mixed with $5 \times$ Laemmli sample buffer and boiled for $4 \mathrm{~min}$. Then, equal amounts of protein $(10 \mu \mathrm{g}$ for all blottings, except for the DARPP-32 and actin detections for which $80 \mu \mathrm{g}$ were loaded), were resolved on $10 \%$ SDS-polyacrylamide gels and transferred onto nitrocellulose membranes (Amersham, Barcelona, Spain). The membranes were blocked for $1 \mathrm{~h}$ at room temperature in $5 \%$ dry skimmed milk (Sveltesse, Nestlé, Barcelona, Spain) in TBST (25 mM Tris, $137 \mathrm{mM} \mathrm{NaCl}, \mathrm{pH}$ $7.4,0.1 \%$ Tween-20) before incubation overnight at $4^{\circ} \mathrm{C}$ with the primary antibody. Primary antibodies were: (i) affinity-purified goat polyclonal anti-DARPP-32 (1:500; Santa-Cruz Biotechnology, Santa-Cruz, CA); (ii) monoclonal anti-synaptophysin (1 : 7000; Sigma, St Louis, MO); (iii) monoclonal anti-GAP-43 (1:1500; Sigma); (iv) affinitypurified rabbit anti-actin (1:500; Sigma); and (v): monoclonal anti- $\alpha$-tubulin (1:30000; Sigma). After extensive washing in $5 \%$ milk-TBST, blots were incubated with peroxidase-conjugated anti-rabbit, anti-goat (Jackson Immunoresearch laboratories, West Grove, PA), or anti-mouse (Bio-Rad) secondary antibodies for $1 \mathrm{~h}$ at room temperature. Finally, blots were washed and the peroxidase reaction was developed by enhanced chemiluminescence (Amersham Biosciences). The intensity of the bands on the immunoblots was quantified by densitometry using the GS-800 Calibrated Densitometer, from Bio-Rad.

To allow for potential variations in protein estimation and gel loading, the expression of DARPP-32 was compared to that of actin in each sample. Synaptophysin and GAP-43 expression was normalized to that of $\alpha$-tubulin. Therefore, the value for each sample is expressed as the percentage of optical density obtained using each corresponding housekeeping protein. The values are expressed as the means \pm SEM of three independent experiments performed.

\section{ELISA}

Serum was prepared by centrifugation at $15000 \mathrm{~g}$ for $5 \mathrm{~min}$, aliquoted and then stored at $-80^{\circ} \mathrm{C}$ until the cytokine assays were performed. Concentrations of IL- $1 \beta$, IL-2, IL-6, IL-12, and TNF- $\alpha$ were determined using commercial ELISA kits (BioSource International, CA 93012, USA), in accordance with the manufacturer's instructions. All samples and standards were assayed in duplicate.

\section{Statistical Analysis}

Data are presented as mean \pm SEM. Student-Newman-Keuls $t$-test and analyses of variance (ANOVA), with Post hoc Student-Newman-Keuls $t$-test when appropriate, were performed using SPSS. Data regarding startle and PPI values in the HAL experiment were analyzed for the effects of prenatal treatment and drug treatment by ANOVA, followed by the posteriori Student-Newman-Keuls $t$-test 
Table I Effect of Prenatal Administration of LPS on Startle Amplitude during Pulse Alone, Auditory and Visual Trials and in the \% PPI

\begin{tabular}{lcc}
\hline & Control & LPS \\
\hline $\begin{array}{l}\text { Startle amplitude } \\
\text { Pulse alone trials }\end{array}$ & $431.5 \pm 45.8$ & \\
Auditory trials & $122.7 \pm 20.4$ & $478.9 \pm 70.5$ \\
$\quad$ Visual trials & $140.7 \pm 16.2$ & $256.9 \pm 51.4 *$ \\
& & $313.5 \pm 66.2 *$ \\
$\%$ PPI & & \\
Auditory & $70.4 \pm 3.4$ & $46.9 \pm 4.6 * *$ \\
Visual & $66.3 \pm 2.9$ & $27.4 \pm 13.7 * *$ \\
\hline
\end{tabular}

Animals were tested for PPI when reaching 6 months of age. Results are expressed as mean \pm SEM ( $n=14-16$ rats per group).

$* p<0.05$, $* * p<0.01$ vs control group (ANOVA followed by Student-

Newman-Keuls $t$-test)

when appropriate. The statistical analysis reported for the effects of cytokines in the HAL experiment corresponds to independent ANOVA for each time studied. The criterion for significance was set at $p<0.05$.

\section{RESULTS}

\section{Prenatal LPS Exposure Disrupts PPI}

PPI was determined by measuring the decrease in the startle response when the acoustic startle-eliciting stimulus was preceded by an auditory or visual prepulse. Table 1 shows startle amplitude values during both pulse and prepulse trials and the percentage of PPI in 6 month old, prenatally LPS-exposed male rats and in the corresponding control animals of experiment 1. Analysis of the data revealed that prenatal LPS did not significantly affect the startle amplitude in pulse alone trials $(\mathrm{F}(1,27)=0.203, p=\mathrm{NS})$. However, prenatally LPS-exposed rats showed higher startle amplitude values than controls when evaluated in both auditory $(\mathrm{F}(1,27)=6.264, p=0.019)$ and visual prepulse $(\mathrm{F}(1,27)=6.264, p=0.014)$ trials. Concerning the PPI data, statistical analysis revealed a significant effect of prenatal LPS treatment $(\mathrm{F}(1,27)=13.489, p<0.001)$. LPS-exposed rats displayed significantly lower auditory $(p=0.003)$ and visual $(p=0.008)$ PPI than control animals. Therefore, as previously reported (Borrell et al, 2002), there is evidence that prenatal LPS exposure disrupts PPI later in life.

\section{Monoamines in the NAC and Striatum of Adult Offspring Prenatally Exposed to LPS}

The effects of prenatal exposure to LPS on the levels of DA and its metabolites, DOPAC and HVA, are shown in Figure 1. In the NAC, DA tissue levels were significantly increased in LPS-exposed rats $(\sim 63 \% ; p=0.007)$, whereas its metabolites failed to show any statistical difference when compared to the corresponding control values (DOPAC: $p=\mathrm{NS}$; HVA: $p=\mathrm{NS}$ ) (Figure 1a). However, in the striatum, neither DA $(p=N S)$ nor HVA $(p=N S)$ tissue levels were altered in LPS-exposed rats, although a significant increase a

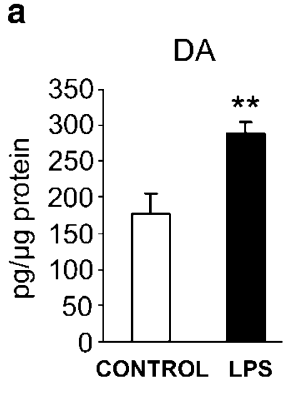

b
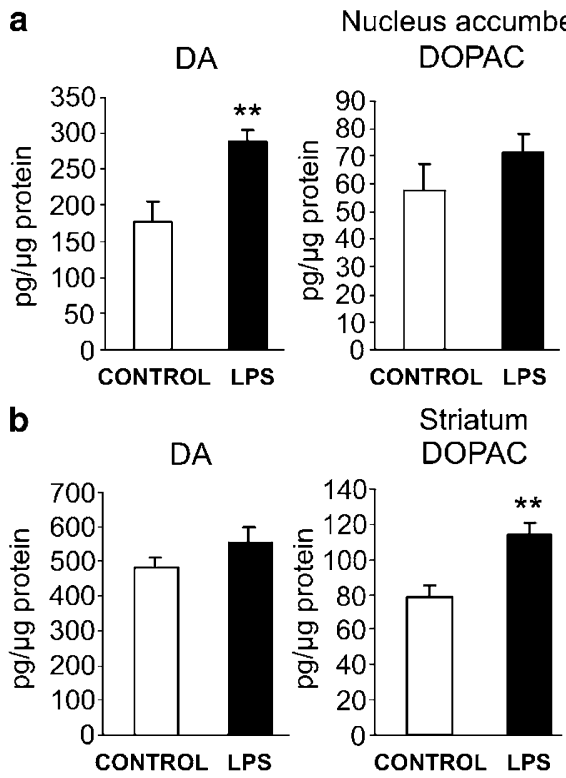

ens

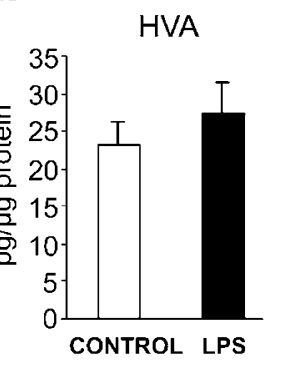

Striatum
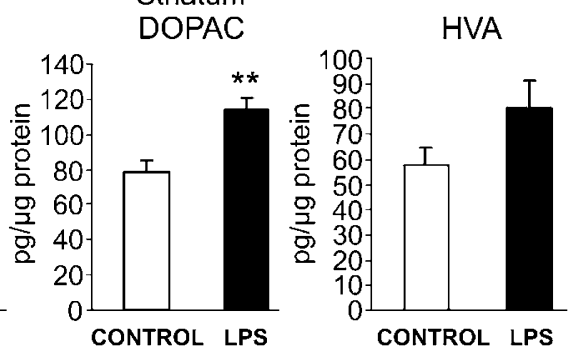

Figure I Tissue levels of DA and its metabolites, DOPAC and HVA, in the NAC (a) and striatum (b) of six-month-old male rats prenatally exposed to LPS. Prenatal LPS exposure significantly increased the DA tissue levels in the NAC and the DOPAC tissue levels in the striatum. Results are expressed as mean \pm SEM ( $n=6$ rats per group). *** $<0.01$ vs control group (Student-Newman-Keuls t-test).

in DOPAC levels in animals exposed to prenatal LPS treatment $v s$ controls was observed $(\sim 43 \% ; p=0.003)$ (Figure 1b). These findings show that prenatal LPS exposure induces alterations in brain dopaminergic function in a region-specific manner.

\section{DARPP-32 Expression in the Frontal Cortex, Hippocampus, and Amygdala of Adult Offspring Prenatally Exposed to LPS}

Expression of DARPP-32 was studied by Western blot analysis in the frontal cortex, the hippocampus and the amygdala of 6-month-old rats from a control group and from a group prenatally exposed to LPS. Figure 2a shows the mean \pm SEM of the densitometric values of DARPP-32 expression, normalized to that of actin, in three independent analyses and a representative Western blot of six control and six prenatally exposed to LPS rats. ANOVA of the data revealed an effect of prenatal treatment in the frontal cortex $(F(1,10)=21.848, p<0.001)$. In this area of the brain the expression of DARPP-32 was significantly decreased in prenatally LPS-exposed rats, as compared to control animals $(\sim 67 \% ; p<0.001)$. However, no difference in DARPP-32 expression was found in the hippocampus $(\mathrm{F}(1,9)=0.481, p=\mathrm{NS})$ or the amygdala $(\mathrm{F}(1,10)=0.392$, $p=\mathrm{NS}$ ) of the same animals.

\section{Presynaptic Protein Expression in the Frontal Cortex, Hippocampus, and Amygdala of Adult Offspring Prenatally Exposed to LPS}

ANOVA of the data related to the expression of synaptophysin, an integral membrane protein of the synaptic vesicle involved in neurotransmitter release (Alder et al, 

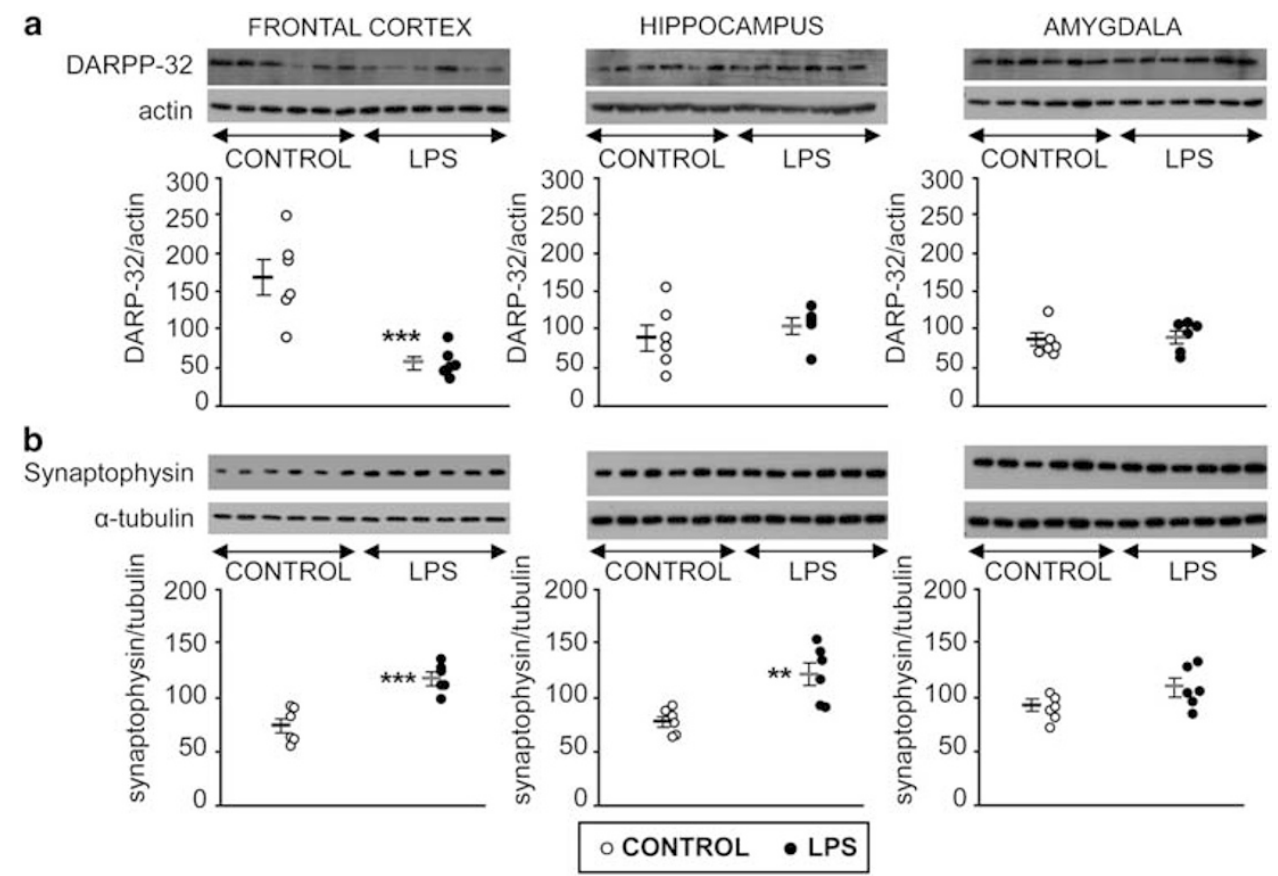

Figure 2 Expression of DARPP-32 and synaptophysin in the frontal cortex, hippocampus, and amygdala of adult rats prenatally exposed to LPS or saline. (a) Representative Western blots and corresponding densitometric analysis (normalized to actin) for DARPP-32 and actin in the frontal cortex, hippocampus, and amygdala of LPS offspring $(n=6)$ and control offspring $(n=6)$. (b) Representative Western blots and corresponding densitometric analysis (normalized to $\alpha$-tubulin) for synaptophysin and $\alpha$-tubulin in the frontal cortex, hippocampus, and amygdala of LPS offspring ( $n=6)$ and control offspring $(n=6)$. Circles represent the mean relative optical density corresponding to each specimen assayed three times independently. Lines represent mean \pm SEM of six animal samples. ${ }^{*} p<<0.0$ I, **** $p<0.00$ I vs corresponding CONTROL group (ANOVA followed by Student-Newman-Keuls $t$-test).

1995), showed a significant effect of prenatal LPS exposure in the frontal cortex $(\mathrm{F}(1,10)=24.568, p<0.001)$ and the hippocampus $(\mathrm{F}(1,9)=12.174, p=0.007)$. In prenatally LPS-exposed rats, synaptophysin expression was significantly higher in the frontal cortex $(\sim 59 \% ; p<0.001)$ and in the hippocampus ( $\sim 49 \% ; p=0.007)$, as compared to control animals (Figure $2 \mathrm{~b}$ ). However, no significant effect of prenatal treatment was found in the amygdala $(\mathrm{F}(1,10)=4.568, p=\mathrm{NS})$.

Regarding GAP-43, a presynaptic membrane protein concentrated within the growth cones and axons (Benowitz and Routtenberg, 1997), a different response pattern was observed as no change was found in the frontal cortex $(\mathrm{F}(1,10)=0.489, p=\mathrm{NS})$, the hippocampus $(\mathrm{F}(1,9)=0.064$, $p=\mathrm{NS})$ or the amygdala $(\mathrm{F}(1,10)=0.997, p=\mathrm{NS})$ (data not shown).

\section{Effect of HAL on PPI}

In experiment 2, we examined the effect of oral treatment $(1.2 \mathrm{mg} / \mathrm{kg})$ with HAL for 14 days on the PPI deficit induced by prenatal LPS exposure, in rats of around 6 months of age. Rats were assessed for their PPI 2 weeks before starting the treatment with HAL, or its VEH, in order to determine whether they had a PPI deficit before the treatment (pretreatment test). Once the treatment had started, PPI tests were performed after the first day, and at the end of the treatment period. We also measured the effect of HAL on PPI reduction induced by prenatal LPS the next day and then 2 weeks after stopping the antipsychotic treatment. Table 2 shows startle amplitude values during both pulse and prepulse trials. ANOVA of the data failed to show any statistical differences owing to the prenatal treatment, in the pulse alone $(\mathrm{F}(1,194)=0.023, p=\mathrm{NS})$ and in the auditory $(\mathrm{F}(1,194)=3.075, p=\mathrm{NS})$ trials. However, a significant effect of prenatal treatment in the visual trials of startle amplitude was observed $(\mathrm{F}(1,194)=11.488, p<0.001)$. The antipsychotic treatment exerted a significant effect on startle amplitude when measured in both pulse alone $(\mathrm{F}(6,194)=6.852, \quad p<0.001) \quad$ and visual pulse trials $(\mathrm{F}(6,194)=9.875, p<0.001)$. No significant effect of antipsychotic treatment on startle amplitude values was observed in auditory trials $(\mathrm{F}(6,194)=0.413, p=\mathrm{NS})$. Analysis of data also revealed a significant prenatal treatment/antipsychotic treatment interaction on startle amplitude in visual trials $(\mathrm{F}(6,194)=3.924, p<0.001)$. Post hoc comparisons of data from the pretreatment test showed that visual startle amplitude values of LPS-exposed rats were higher than controls $(p=0.006)$. Post hoc comparisons of data from the first day of treatment test showed that values of startle amplitude in the auditory and visual trials were higher in the LPS + VEH group, when compared to control + VEH (auditory: $p=0.009$; visual: $p<0.001$ ) or LPS + HAL (auditory: $p<0.001$; visual: $p<0.001$ ). Post hoc comparisons of data from the last day of treatment test showed that values of pulse alone startle amplitude were significantly higher in both control + HAL $(p=0.02)$ and LPS + HAL $(p=0.02)$, compared with the control + VEH group.

Concerning the PPI, ANOVA of the data revealed a significant effect of prenatal treatment $(\mathrm{F}(1,177)=32.932$, $p<0.001)$, a significant effect of HAL treatment 
Table 2 Startle Amplitude Values during Both Pulse and Prepulse Trials in Rats of Around 6 Months of Age Prenatally Exposed to LPS or Saline (Control)

\begin{tabular}{|c|c|c|c|c|c|c|}
\hline \multirow[b]{2}{*}{ Startle amplitude } & \multicolumn{2}{|c|}{ Pulse alone trials } & \multicolumn{2}{|c|}{ Auditory trials } & \multicolumn{2}{|c|}{ Visual trials } \\
\hline & Control & LPS & Control & LPS & Control & LPS \\
\hline \multicolumn{7}{|l|}{ First day of treatment } \\
\hline \multicolumn{7}{|l|}{ Last day of treatment } \\
\hline VEH & $422.4 \pm 39.0$ & $501.4 \pm 49.2$ & $132.7 \pm 29.2$ & $181.6 \pm 22.4$ & $122.1 \pm 22.0$ & $|4| .2 \pm \mid 4.7$ \\
\hline HAL & $607.4 \pm 31.6^{f}$ & $610.7 \pm 30.0^{f}$ & $203.6 \pm 26.5$ & $174.9 \pm 20.3$ & $114.5 \pm 17.5$ & $98.4 \pm 11.5$ \\
\hline \multicolumn{7}{|l|}{ After HAL treatment } \\
\hline $\begin{array}{l}\text { Tests were done: befor } \\
\text { or two weeks after the } \\
\text { group for the others). } \\
a_{p}<0.0 \text { I vs control+V } \\
b_{p}<0.0 \text { I vs control+VE } \\
c_{p}<0.00 \text { I vs control+ } \\
{ }_{p} p<0.05 \text { vs LPS+VEH } \\
e_{p}<0.00 \text { I vs LPS+VEI } \\
f_{p}<0.05 \text { vs control+VE }\end{array}$ & $\begin{array}{l}\text { g a treatment } w \\
\text { HAL treatment } \\
P \text { in the pretrea } \\
P \text { in the first da } \\
\text { up in the first } d \\
\text { the first day o } \\
\text { in the first day } \\
D \text { in the last day }\end{array}$ & $\begin{array}{l}(1.2 \mathrm{mg} / \mathrm{kg}) \text { or i } \\
\mathrm{s} \text { are expressec } \\
\text { est. } \\
\text { atment test. } \\
\text { eatment test. } \\
\text { ent test. } \\
\text { nent test. } \\
\text { tment test (AN }\end{array}$ & $\begin{array}{l}\text { or } 14 \text { days (pre } \\
n \pm \operatorname{SEM}(n=2\end{array}$ & $\begin{array}{l}\text { t); then on the } \\
\text { s per group fo }\end{array}$ & $\begin{array}{l}\text { he last days of } \\
\text { reatment test }\end{array}$ & $\begin{array}{l}\text { t; and one day } \\
2 \pm 2 \text { rats per }\end{array}$ \\
\hline
\end{tabular}

$(\mathrm{F}(6,177)=12.440, p<0.001)$ and a significant prenatal treatment/antipsychotic treatment interaction $(\mathrm{F}(6,194)=$ $5.119, p<0.001)$. In the pretreatment PPI evaluation, LPSexposed rats showed significantly lower auditory $(p<0.001)$ and visual $(p<0.001)$ PPI than control rats (Figure 3$)$. As regards the first day of treatment PPI data, post hoc tests indicated that prenatally LPS-exposed rats treated with VEH showed significantly lower auditory $(p=0.006)$ and visual $(p=0.002)$ PPI than the animals of the corresponding control group (Figure 4a). HAL treatment did not significantly affect auditory $(p=\mathrm{NS})$ or visual $(p=\mathrm{NS})$ PPI values in control animals. However, HAL significantly reversed PPI deficit induced by the prenatal administration of LPS for both prepulse stimulus modalities, auditory $(p=0.026$ vs LPS + VEH group; $p=\mathrm{NS} v s$ control $+\mathrm{HAL}$ group) and visual ( $p=0.011 v s$ LPS $+\mathrm{VEH}$ group; $p=\mathrm{NS} v s$ control + HAL group) (Figure $4 \mathrm{a}$ ). On the last day of treatment, animals treated with $\mathrm{VEH}$ showed a significant reduction in auditory PPI induced by prenatal LPS $(p=0.020)$, but the comparison between prenatally LPSexposed rats and the corresponding control animals for visual PPI failed to show a statistical difference $(p=\mathrm{NS})$. Indeed, animals exposed to LPS and treated with VEH displayed a slightly reduced visual PPI deficit on the last day of treatment (Figure $4 \mathrm{~b}$ ), compared with the same animals on the first day of treatment (Figure 4a). HAL treatment for 14 days significantly reversed the auditory PPI deficit induced by prenatal LPS administration $(p=0.021 v s$ LPS + $\mathrm{VEH}$ group; $p=\mathrm{NS}$ vs control $+\mathrm{HAL}$ group), without affecting the visual PPI in these animals $(p=N S)$ or the

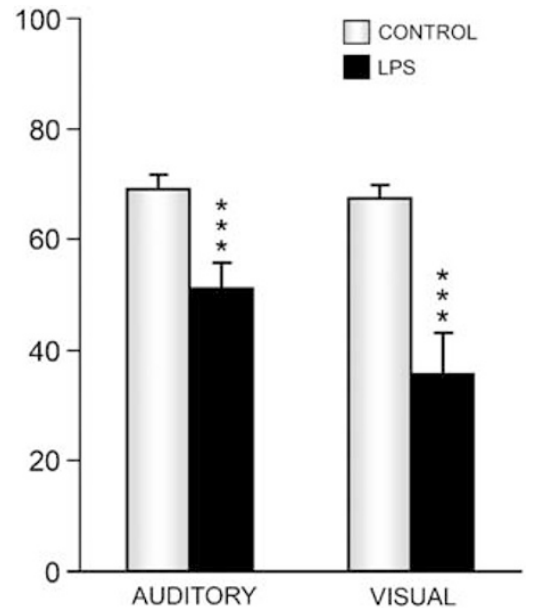

Figure 3 Percentage of auditory and visual PPI in rats 150 days old that had been prenatally exposed to LPS or saline (pretreatment with HAL or VEH test). Results are expressed as mean \pm SEM $(n=24 \pm 2$ rats per group). $* * * *<0.001$ vs control group (ANOVA followed by StudentNewman-Keuls t-test).

PPI in control animals (auditory: $p=\mathrm{NS}$; visual: $p=\mathrm{NS}$ ) (Figure $4 \mathrm{~b}$ ). These data indicate that both 1 and 14 days of oral treatment with the typical antipsychotic HAL reverses the auditory PPI deficit and ameliorates the visual PPI deficit observed in adult rats prenatally exposed to LPS.

The auditory and visual PPI of prenatally LPS-exposed male rats, and the corresponding control animals, the next day and 2 weeks after stopping $\mathrm{HAL}$ are illustrated in 


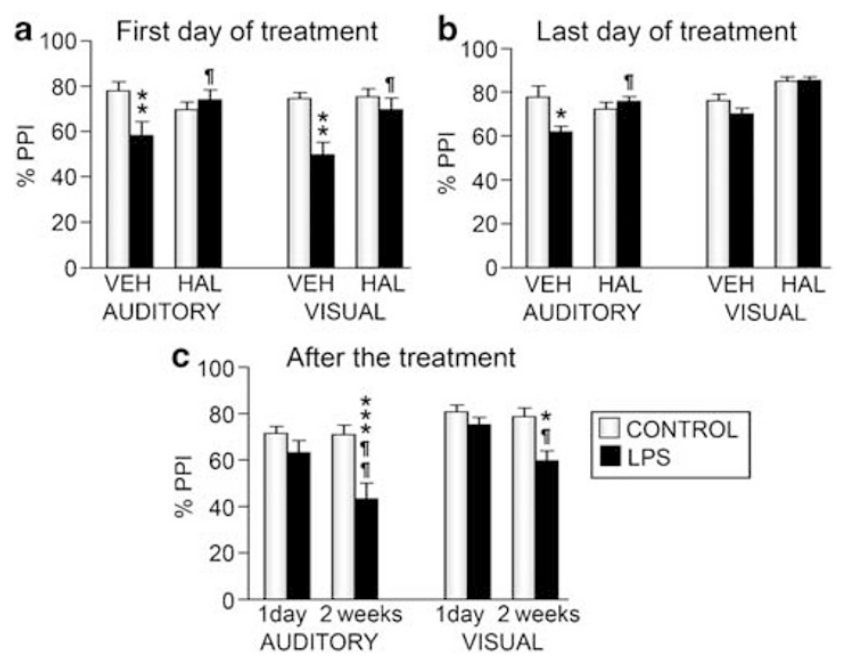

Figure 4 Effect of HAL on auditory and visual PPI in adult rats prenatally exposed to LPS or saline (CONTROL). HAL (approximately $1.2 \mathrm{mg} / \mathrm{kg}$ ) or VEH were administered in the drinking water during 14 consecutive days and animals were tested for PPI: (a) the first day of treatment, (b) the last day of treatment and (c) I day and 2 weeks after stopping the HAL. Results are expressed as mean \pm SEM $\left(n=9-1 \mid\right.$ rats per group). ${ }^{*} p<0.05$, *** $p<0.0$ I, **** $p<0.001$ vs control group; $p<0.05$, ${ }_{p}<0.01$ vs the corresponding VEH group in (a) and (b) and vs LPS I day group in (c) (ANOVA followed by Student-Newman-Keuls t-test).

Figure 4c. The day after HAL deprivation, animals prenatally exposed to LPS did not show any significant differences in PPI, with respect to the control group (auditory: $p=\mathrm{NS}$; visual: $p=\mathrm{NS}$ ). However, 2 weeks later LPS-exposed rats displayed significantly lower PPI for both auditory $(p=0.003)$ and visual $(p=0.016)$ prepulse stimuli compared with the control animals. Therefore, HAL improvement of PPI deficit induced by prenatal LPS exposure is maintained the day after stopping a treatment regimen of 14 days with the antipsychotic drug, but this is not the case 2 weeks later.

\section{Effect of HAL on Serum Cytokine Levels}

In order to assess the alterations in serum cytokine levels induced by prenatal LPS exposure, and the effects of HAL in adult rats, three different groups were compared. The first group (without HAL) corresponded to rats in which no treatment with HAL or VEH was carried out. Serum samples were obtained from animals used in experiment 1 for PPI assays (Figure 5a). Second and third groups corresponded to rats from experiment 2 in the PPI assays. Serum samples were obtained from animals killed 1 day or 2 weeks after stopping a 14-day treatment with HAL (group HAL and HAL +2 weeks, respectively) (Figure $5 b$ and $c$ ). The serum concentrations of IL- $1 \beta$, IL-2, IL-6, IL-12, and TNF- $\alpha$ were measured (Figure 6).

Regarding serum IL- $1 \beta$ levels, statistical analysis revealed no significant effect of prenatal LPS treatment $(\mathrm{F}(1,65)=3.066, p=\mathrm{NS})$. A significant effect of treatment with HAL $(\mathrm{F}(2,65)=4.941, p=0.010)$ and a significant prenatal treatment/antipsychotic treatment interaction were observed $(\mathrm{F}(2,65)=25.439, p<0.001)$. Post hoc tests indicated that 2 weeks after stopping HAL treatment, control rats showed an increase in serum IL- $1 \beta$ levels, as compared

\section{a Group without $\mathrm{HAL}$}

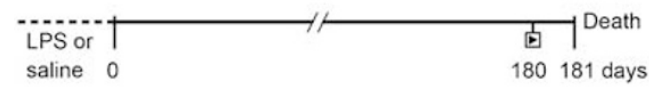

b Group HAL

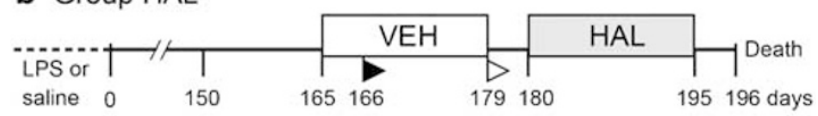

c Group $\mathrm{HAL}+2$ weeks

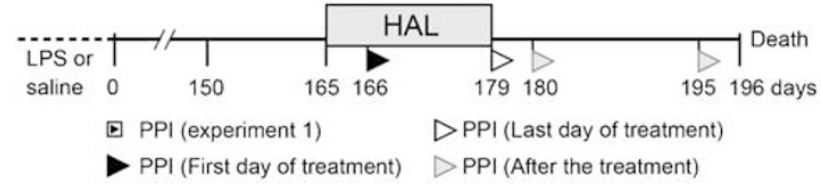

Figure 5 Groups compared in assessing the effects of prenatal LPS exposure on serum cytokine levels and the effects of HAL on serum cytokine levels in adult rats prenatally exposed to LPS or saline (control). (a) Animals were tested for PPI when they were 180 days old and then they were killed the next day. Brains were removed for neurochemical analyses and trunk blood was collected for cytokine assays. (b) Animals were tested for PPI when they were 150 days old, before being subjected to a treatment with VEH for 14 days (pretreatment-test), and the first and the last days of treatment ( 166 and 179 day). At I 80 days old they were treated with HAL for 14 days and killed I day after HAL deprivation. Trunk blood was collected for cytokine assays. (c) Animals were tested for PPI when they were 150 days old (pretreatment-test). Animals were treated with HAL for 14 days (from day 165 to 179). They were evaluated for PPI on the first and the last day of treatment and I day and 2 weeks later. Animals were killed the next day and trunk blood was collected for cytokine assays.

to control rats without HAL $(p<0.001)$ or rats killed 1 day after the end of the HAL treatment $(p=0.003)$. No effect of HAL was observed in prenatal LPS-exposed rats (Figure 6a).

ANOVA of the data related to serum IL-12 levels did not show any significant effect of prenatal treatment $(\mathrm{F}(1,65)=$ $2.761, p=\mathrm{NS})$ or treatment with $\mathrm{HAL}(\mathrm{F}(2,65)=1.393$, $p=\mathrm{NS})$. However, a significant prenatal treatment/antipsychotic treatment interaction was observed $(\mathrm{F}(2,65)=5.965$, $p=0.004)$. Control rats killed 2 weeks after stopping HAL treatment showed a significant increase in serum IL-12 levels, as compared to control rats without HAL treatment $(p=0.041)$. However, prenatal LPS-exposed rats killed the following day, or 2 weeks after the end of HAL treatment, showed a significant decrease in serum IL-12 levels, as compared to LPS-exposed rats from the group without HAL treatment ( $p=0.008$ and $p=0.010$, respectively) (Figure 6b).

As regards serum IL-2 levels, a significant effect of prenatal LPS treatment was observed $(\mathrm{F}(1,65)=12.365$, $p<0.001)$. Prenatal LPS exposure augmented the serum levels of IL-2 $(p<0.001)$. A significant effect of HAL treatment $(\mathrm{F}(2,65)=5.199, p=0.008)$ and a significant prenatal treatment/antipsychotic treatment interaction $(\mathrm{F}(2,65)=25.439, p<0.001)$ were observed. Control rats, killed 2 weeks after stopping HAL treatment, showed significantly increased serum IL-2 levels, as compared to control rats without HAL treatment $(p=0.002)$. However, in prenatally LPS-exposed rats, HAL treatment decreased the serum IL-2 levels, when measured the next day $(p<0.001)$ and then 2 weeks $(p<0.001)$ after the end of the antipsychotic treatment (Figure $6 \mathrm{c}$ ). 


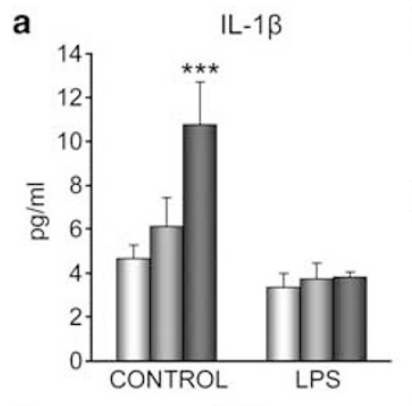

b IL-12
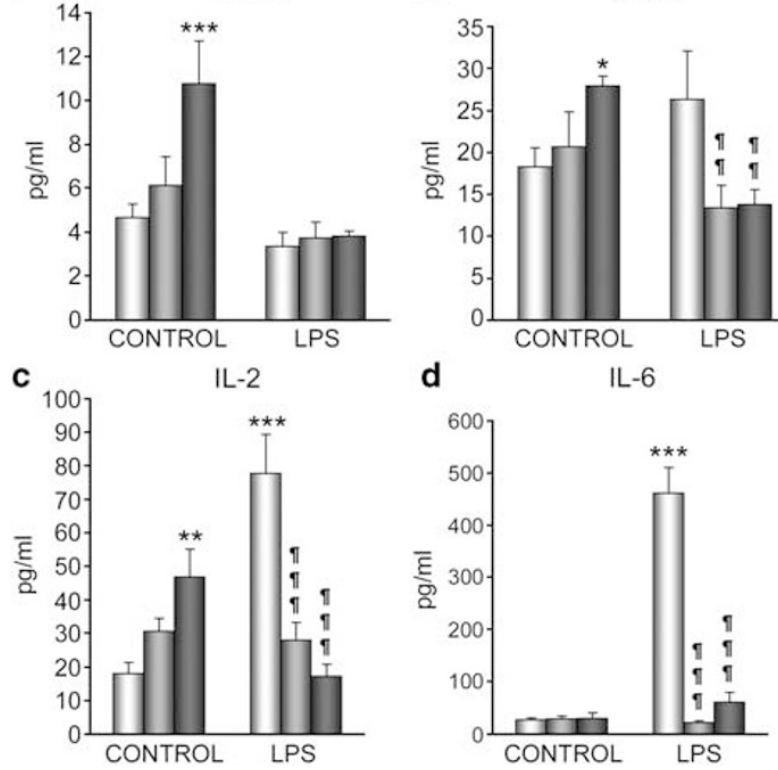

e

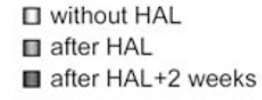

Figure 6 Serum levels of IL-I $\beta$ (a), IL-I2 (b), IL-2 (c), IL-6 (d), and TNF- $\alpha$ (e) of adult rats prenatally exposed to LPS or saline (CONTROL) (without the $\mathrm{HAL}$ group) and the effect of an oral treatment for 14 days with HAL, I day after stopping the treatment (after HAL) or 2 weeks later (after HAL +2 weeks), on serum cytokine levels of adult LPS or control rats. Results are expressed as mean \pm SEM $(n=12 \pm 2$ rats per group). $* p<0.05$, **** $p<0.01$,

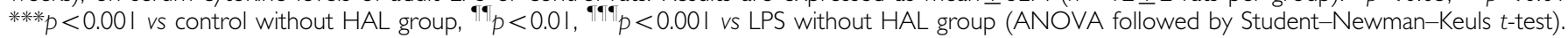

With respect to serum IL-6 levels, a significant effect of prenatal LPS treatment was observed $(\mathrm{F}(1,65)=82.259$, $p<0.001)$. Prenatal LPS exposure increased the serum levels of IL-6 $(p<0.001)$. A significant effect of HAL $(\mathrm{F}(2,65)=69.109, \quad p<0.001)$ and a significant prenatal treatment/antipsychotic treatment interaction $(\mathrm{F}(2,65)=$ 70.576, $p<0.001)$ were observed. Although treatment with HAL failed to modify serum IL-6 levels in control rats, it decreased the serum IL-6 levels in prenatally LPS-exposed rats, observed the following day $(p<0.001)$ and 2 weeks $(p<0.001)$ after stopping treatment with the antipsychotic drug (Figure 6d).

As regards serum TNF- $\alpha$ levels, a significant effect of prenatal LPS treatment was observed $(\mathrm{F}(1,65)=179.439$, $p<0.001)$. Prenatal LPS exposure significantly augmented serum levels of TNF- $\alpha(p<0.001)$. A significant effect of HAL $(\mathrm{F}(2,65)=19.693, p<0.001)$ and a significant prenatal treatment/antipsychotic treatment interaction $(\mathrm{F}(2,65)=$ 19.693, $p<0.001$ ) were also found. In control animals, serum TNF- $\alpha$ levels were practically undetectable before and after treatment with HAL. In prenatal LPS-exposed rats, HAL had reduced serum TNF- $\alpha$ levels when measured the day after stopping the antipsychotic treatment $(p<0.001)$, but this effect was not observed 2 weeks later $(p=\mathrm{NS})$ (Figure 6e).

\section{DISCUSSION}

\section{Altered Dopaminergic Neurotransmission in PPI-Deficient LPS-Exposed Rats}

In agreement with our previous report (Borrell et al, 2002), this study demonstrates that a prenatal immune challenge, provoked by LPS exposure during gestation, disrupts PPI in adult life, and further supports the critical influence of perinatal events on information processing at an adult age (Ellenbroek et al, 1998; Shi et al, 2003; Tohmi et al, 2004).

In the present study, prenatally LPS-exposed rats show significantly increased levels of DA in the NAC without significant changes in levels of its metabolites DOPAC and HVA. This supports our previous observations of an increase in tyrosine hydroxylase immunoreactivity in the NAC of adult rats prenatally exposed to LPS (Borrell et al, 2002). The NAC is a key subcortical integrative hub, connecting forebrain and limbic structures that control cognition and behavior (Swerdlow and Koob, 1987). It has been suggested that the deleterious effects of DA agonists on PPI are mediated, in part, by increased DA activity in the NAC (Humby et al, 1996; Swerdlow et al, 1986). Therefore, the increased DA levels in the NAC of prenatally LPSexposed rats might contribute to the PPI deficit. Although less consistently, the anteromedial striatum has also been reported to be involved in sensorimotor gating regulation as dopaminergic overactivation in this region results in PPI disruption (Swerdlow et al, 1986). Here, no significant difference in striatal DA between prenatally LPS-exposed or control rats was found, although DOPAC levels were significantly elevated in prenatally LPS-exposed animals. The distinct patterns of changes in different brain areas (NAC vs striatum) indicate that prenatal LPS treatment affecting dopaminergic function might be region-specific, hence the relevance of these brain areas in sensorimotor gating processing.

One well-characterized mediator of the biochemical, electro-physiological, transcriptional, and behavioral effects of DA is DARPP-32 (Fienberg et al, 1998). The D1 subclass of DA receptors and the $N$-methyl-D-aspartate (NMDA) subclass of glutamate receptors regulate, in opposite directions, the amount of phosphorylated activated DARPP-32 (Snyder et al, 1998). In this work, we found 
that the total amount of DARPP-32 protein had decreased in the frontal cortex of adults rats submitted to prenatal LPS treatment. This reduction is not generalized to all brain regions, as no change was observed in the hippocampus or in the amygdala of the same animals. Interestingly, it has been suggested that the medial prefrontal cortex is an important region within the neuronal circuit responsible for NMDA receptor antagonist-induced sensorimotor gating deficit in rats (Schwabe and Koch, 2004). Thus, considering the key regulatory role of DARPP-32 in DA and glutamate function (Snyder et al, 1998), the decreased availability of DARPP-32 in the frontal cortex could contribute to the sensorimotor deficit observed in adult rats prenatally exposed to LPS. An important role of the prefrontal cortex in the PPI deficits of schizophrenic patients has been reported (Hazlett et al, 1998). Prefrontal hypodopaminergia has also been implicated as a critical feature of the neural circuit disturbances that accompany this disorder (Karson et al, 1999). Interestingly, a selective decrease in DARPP-32 protein levels has been reported in the prefrontal cortex of patients with schizophrenia (Albert et al, 2002), suggesting that such an abnormality could contribute to the compromised prefrontal dysfunction associated with the illness. Because hypofunction of prefrontal cortical DA leads to excessive DA release in the NAC (Deutch, 1992), the reduced expression of DARPP-32 in the frontal cortex of prenatally exposed-rats could reflect a hypofunctionality of this region which might contribute to the elevated level of $\mathrm{DA}$ in the NAC of the same animals.

\section{Prenatal LPS Exposure Enhances Expression of Synaptophysin in Adult Rats}

Synaptophysin is the most established, best characterized and widely used synaptic protein, usually referred to as a marker of synaptic density (Wiedenmann and Franke, 1985). Its role in the synaptic vesicle life cycle is still relatively unknown, although it is now almost universally agreed that it may have a role in determining synaptic strength (Evans and Cousin, 2005). In the present study, the expression of synaptophysin was increased in the frontal cortex and hippocampus of rats prenatally exposed to LPS, at the age of 6 months, in the absence of changes in GAP-43. GAP-43 is another presynaptic protein that participates in mechanisms of axonal path finding during development, as well as in the regulation of neurotransmitter release and synaptic plasticity in mature synapses (Benowitz and Routtenberg, 1997). The distinct expression patterns of these two synaptic markers observed in the present study indicate that prenatal exposure to LPS impairs synaptic functioning by presynaptic protein-specific mechanisms. It could be argued that as synaptophysin is a protein of the small presynaptic vesicles (Wiedenmann and Franke, 1985), and GAP-43 is concentrated in growth cones and axons (Benowitz and Routtenberg, 1997), the observed pathology could be restricted to the small presynaptic vesicles of the synapse, or to neuronal populations containing small, but not large, synaptic vesicles. The higher levels in synaptophysin expression observed in the frontal cortex and hippocampus of adult prenatally LPS-exposed rats could be interpreted as an increase in the synaptic density in those structures, reflecting an altered axonal arborization or projection of the neurons. Accordingly, a recent report shows that maternal inflammation, induced by LPS at gestation day 17, specifically increased the number of pyramidal and granular cells in the hippocampus, as well as the size of pyramidal cells, later in life (Golan et al, 2005). Alternatively, the increased synaptophysin expression observed may be due to a differing number or composition of synaptic vesicles. In this respect, a recent study investigating whether experimental manipulation of prefrontal cortical development in rats alters prefrontal synaptic protein levels in adults, detected an increased immunoreactivity for the synaptic vesicle protein VAMP (synaptobrevin/vesicle-associated membrane protein), although changes in other presynaptic proteins were not observed (Halim et al, 2003). The same work reported that VAMP immunoreactivity was lower in patients with schizophrenia than in controls and suggested that apparently profound prefrontal cortical dysfunction in schizophrenia, as well as in an animal model of schizophrenia, may exist without gross changes in the abundance of many synaptic proteins, though discrete changes in selected presynaptic molecules may occur (Halim et al, 2003). Either way, the changes in synaptophysin expression in the frontal cortex and hippocampus observed in prenatally LPS-exposed adult rats are likely to be associated with impaired synaptic functioning, and they provide a plausible anatomical basis for the suggestion of aberrant functional connectivity in those brain regions. It may be speculated that, at least in the frontal cortex, the increase in the presynaptic protein synaptophysin expression observed in the PPI-deficient prenatally LPS-exposed rats could reflect a compensatory mechanism generated in response to the postsynaptic DARPP-32 reduction mentioned above and/or a reduction in the number or the size of dendritic spines. Supporting the last hypothesis, a recent work shows that the downregulation of drebrin-A protein levels, a protein located in dendritic spines which regulates their morphological changes, impairs PPI in rats (Kobayashi et al, 2004). In addition, in vitro studies suggest that maternal inflammation can alter cortical neuron dendrite development through a cytokine-mediated mechanism (Gilmore et al, 2004).

The increased levels of synaptophysin in the frontal cortex and hippocampus of prenatally LPS-exposed rats are not consistent with the mostly reduced levels found in the brains of patients with schizophrenia using in situ hybridization histochemistry, immunoautoradiography, and Western blotting analysis (Eastwood, 2004; Karson et al, 1999). Microarray studies also highlight the lower levels of synaptophysin in schizophrenic brains, along with other presynaptic markers (Mirnics et al, 2006). One of the fundamental issues associated with post-mortem studies of gene expression is that they are only able to examine a snapshot of the events that may be taking place in the brain in schizophrenia. It is not possible to determine whether changes in the expression of the genes of interest reflect incidents immediately before death or are representative of ongoing molecular changes that may have been present throughout the lifetime of the subject (Eastwood, 2004). Although pathology of the presynaptic machinery seems to be a robust finding in schizophrenia, it remains to be elucidated if that synaptic pathology is developmental in origin. In mice, human influenza infection at day 9 of 
pregnancy augments the expression of the synaptosomeassociated protein $25 \mathrm{kDa}$ (SNAP-25) in a layer-specific and region-dependent manner in day 0 neonates (Fatemi et al, 1998). This study, along with the data presented here, indicates that an immune challenge in utero can alter presynaptic protein expression later in life. Further studies are needed to determine whether these alterations are differently expressed throughout the lifetime of the animals.

\section{HAL Alleviates PPI and Immune Alterations Induced by Prenatal LPS Exposure}

Consistent with the clinical pharmacology of schizophrenia, oral antipsychotic HAL treatment for 1 and 14 consecutive days restored the auditory PPI deficit induced by prenatal LPS exposure. Under the conditions used in the present study, visual PPI deficit induced by LPS was slightly reduced in VEH-treated animals on the last day of treatment, compared with the same animals on the first day of treatment. This makes it difficult to interpret the antipsychotic effect, after the first day of treatment, on the visual PPI deficit induced by prenatal LPS exposure. However, the LPS animals treated with HAL for 14 days showed no differences compared to the control group on the last day of treatment. These LPS-exposed animals dispayed a visual PPI deficit 2 weeks after the end of such treatment. This indicates that HAL was effective in restoring PPI during its administration. Previously we have reported (Borrell et al, 2002) that not only the intraperitoneally acute administrations of the typical antipsychotic drug HAL, but also administration of the atypical clozapine, were effective in restoring the PPI deficit induced by LPS treatment during pregnancy. Thus, our study provides additional evidence that a neurodevelopmentally induced PPI disruption can be alleviated by antipsychotic treatment. In addition, under the conditions used in the present work, the positive effect on altered PPI of a 14-day treatment with HAL disappears 2 weeks later, when prenatally LPS-exposed animals again display a disruption in PPI. Thus, prenatal LPS exposure in rats may become useful for identifying potential novel compounds capable of restoring PPI and able to extend their effects beyond the end of treatment.

Interestingly, prenatal LPS exposure increases the serum levels of cytokines in adults, an effect which is also reversed by HAL. In particular, prenatal LPS exposure in rats augments serum levels of IL-2, IL- 6 , and TNF- $\alpha$, without affecting IL- $1 \beta$ or IL-12, at the age of 6 months. These observations extend our previous results, in which prenatal LPS-exposed rats showed increased serum levels of IL-2 at the age of 100 and 300 days and serum IL-6 levels at 100 days of age (Borrell et al, 2002) and they highlight that changes in serum IL-6 levels induced by prenatal LPSexposure seem to be age-dependent. Several studies show increased levels of IL-6 in patients with schizophrenia (Monteleone et al, 1997; Pae et al, 2006). Moreover, it has been recently suggested that IL- 6 may be involved in the clinical symptomatology and clinical improvement of schizophrenia (Pae et al, 2006). Nonetheless, there is an increasing body of evidence that cytokine abnormalities play a role in the pathophysiology of schizophrenia, and encouraging results and some controversial findings have been simultaneously produced. The first limitation in current cytokine research concerning schizophrenia is the inconsistent replications of laboratory findings, particularly the measurements of cytokines (Kim et al, 2004). Our data suggest that age could be an important confounding factor which may participate in the heterogeneous, and often contradictory, results in this field. Along with an increase in IL-6, prenatally LPS-exposed rats also show elevated serum levels of IL-2 and TNF- $\alpha$. Higher concentrations of IL-2 in plasma (Kim et al, 2004) and cerebrospinal fluid (CSF) (Licinio et al, 1993; McAllister et al, 1995), as well as higher plasma levels of TNF- $\alpha$ (Monteleone et al, 1997), have been found in patients with schizophrenia. Thus, in the present study, sensorimotor gating deficient LPS-exposed rats displayed, to some extent, immune alterations similar to those reported in patients with schizophrenia.

Peripheral IL-6 may cross the blood-brain barrier (BBB) by an active transport mechanism (Banks et al, 1994), acting in the CNS through specific receptors (Schobitz et al, 1993). It has been suggested that lymphocyte-derived IL-2 crosses the intact BBB (Waguespack et al, 1994), and may gain access to IL-2 receptors on neuronal and glial cells (Araujo et al, 1989), and also an active transport mechanism from blood to brain has been documented for TNF- $\alpha$ (Gutierrez et al, 1993). Chronic peripheral administration of IL-2 has been associated with rat hippocampal neurodegeneration and the suppression of hippocampal long-term potentiation (LTP) (Tancredi et al, 1990), leading to impaired memory performance (Nemni et al, 1992), and with suppression of afferent sensory transmission in the primary somatosensory cortex, leading to poor spatial learning (Park et al, 1995). In addition, IL-2 induces behavioral changes that are associated with alterations in central dopaminergic processes (Zalcman, 2002). In vivo, IL-6 mRNA is upregulated by LTP (Jankowsky et al, 2000) and it has been suggested that this cytokine might act as a 'filter' in the fine tuning of consolidation by limiting the long-term storage of some types of information (Balschun et al, 2004). In rats, prenatal exposure to IL-6 increases serum levels of this cytokine and results in inflammatory neurodegeneration in the hippocampus and impaired spatial learning, later in life (Samuelsson et al, 2006). Interestingly, IL-2 and IL-6 in the rodent brain are expressed in selected regions (including the hippocampus, frontoparietal cortex, striatum, and septum) (Araujo et al, 1989; Gadient and Otten, 1994) which are directly implicated in the cortico-striato-pallido-pontine gating circuitry (Swerdlow and Geyer, 1998). Therefore, the disrupted PPI observed in prenatally LPS-exposed rats might be attributable to CNS disturbances provoked by the increased IL-2 and/or IL- 6 and/or TNF- $\alpha$ circulating levels. Recently, it has been reported that maternal LPS, as well as maternal poly I:C exposure, causes a decrease in TNF- $\alpha$ level in the neonatal brain (Gilmore et al, 2005). This observation leads us to speculate that the increased serum level of TNF- $\alpha$ observed in the prenatally LPS-exposed rats could reflect a compensatory mechanism generated in response to a decreased level of this cytokine in the brain. Interestingly, it has been recently reported that the effects of maternal poly I:C exposure between the middle and late gestation periods in mice are dissociable in terms of the cytokine responses in the fetal brain and of the pathological consequences in brain and behavior later in life (Meyer et al, 2006). In agreement with Meyer et al (2006) further 
experiments carried out in our laboratory suggest that the time of prenatal LPS exposure determines the changes in adult serum cytokine levels and PPI deficit (unpublished data).

Treatment with HAL decreased IL-2, IL-6, and TNF- $\alpha$ serum levels in prenatally LPS-exposed rats. Surprisingly, HAL also exerted an effect in control animals but in a different way, that is, inducing a long-term increase in serum IL-1 $\beta$, IL-2, and IL-12 levels. In prenatally LPSexposed rats, reductions in the serum levels of IL-2 and IL-6 were still observed 2 weeks after stopping HAL treatment. However, at the same time, serum TNF- $\alpha$ levels were increased in prenatally exposed rats, which appears to be paralleled by the reappearance of PPI disruption in the same animals. It remains to be determined whether or not peripheral TNF- $\alpha$ could influence PPI, and the possible consequences on disrupted PPI induced by prenatal LPS exposure. HAL treatment decreases both serum (Monteleone et al, 1997) and CSF (McAllister et al, 1995) levels of IL-2 in patients with schizophrenia. A recent study has shown that IL-6 plasma levels in patients with schizophrenia, after antipsychotic treatment, is lower than before (Pae et al, 2006). In addition, antipsychotics normalize the higher amounts of TNF- $\alpha$ released from monocytes isolated from the peripheral blood of patients with schizophrenia and stimulated by LPS (Kowalski et al, 2001). Although it has been suggested that antipsychotics may have immunomodulatory effects on some cytokines and their receptors, it is still debatable as to how antipsychotics show an immunomodulatory activity in patients with schizophrenia (Drzyzga et al, 2006). Our study clearly indicates a different response to antipsychotics of the serum levels of cytokines in pathological or normal physiological states.

Overall, our data broadly support the critical influence of perinatal events on developmental synaptic processes and the putative consequences at an adult age. Here, pregnant rats were submitted to the well-documented LPS-induced immune challenge (Borrell et al, 2002) and, therefore, it seems likely that this anomalous immune influence, interfering with normal fetal development, might give rise to the observed synaptic, neurobehavioral, and immunological dysfunctions in adult offspring. It has been recently reported that the effects of maternal LPS exposure on the developing fetal brain are not mediated by the direct action of LPS but via indirect actions at the level of the maternal circulation or placenta (Ashdown et al, 2006). Among the proteins produced by the maternal inflammatory response are the proinflammatory cytokines. In addition to the stimulation of a cell-death program, cytokines have been shown to affect the survival (Yang et al, 2002), differentiation (Jarskog et al, 1997), and morphology (Gilmore et al, 2004; Golan et al, 2004) of developing neural cells. Whatever the precise mechanisms underlying the influence of immune stimulation during pregnancy, the present findings show that such stimulation leads to changes in PPI and cytokine levels which are ameliorated by HAL, together with an altered synaptic functioning in brain areas related to sensorimotor information processing. In summary, a possible conclusion drawn from the present study is that prenatal immune overactivation affecting neurodevelopment may cause persistent neurophathological and immune abnormalities, resulting in a sustained dysfunction of the mechanisms involved in sensory information processing. An understanding of the mechanisms underlying prenatal infection-induced PPI disruption may have implications for a variety of neuropsychiatric diseases with known or suspected perinatal origins.

\section{ACKNOWLEDGEMENTS}

We thank Rufino Fernandez for his excellent technical assistance during the course of this investigation and María González for generating the HPLC data. We thank Frederic Flamant for critical reading of the manuscript. This work was supported by Fondo de Investigación Sanitaria (FIS) Grant number 01/1138, Fundació La Marató de TV Grant number 014931 and Comunidad de Madrid Grant number 08.5/0020/2001.

\section{REFERENCES}

Albert KA, Hemmings Jr HC, Adamo AI, Potkin SG, Akbarian S, Sandman CA et al (2002). Evidence for decreased DARPP-32 in the prefrontal cortex of patients with schizophrenia. Arch Gen Psychiatry 59: 705-712.

Alder J, Kanki H, Valtorta F, Greengard P, Poo MM (1995). Overexpression of synaptophysin enhances neurotransmitter secretion at Xenopus neuromuscular synapses. J Neurosci 15: 511-519.

Araujo DM, Lapchak PA, Collier B, Quirion R (1989). Localization of interleukin-2 immunoreactivity and interleukin-2 receptors in the rat brain: interaction with the cholinergic system. Brain Res 498: 257-266.

Ashdown H, Dumont Y, Ng M, Poole S, Boksa P, Luheshi GN (2006). The role of cytokines in mediating effects of prenatal infection on the fetus: implications for schizophrenia. Mol Psychiatry 11: 47-55.

Balschun D, Wetzel W, Del Rey A, Pitossi F, Schneider H, Zuschratter W et al (2004). Interleukin-6: a cytokine to forget. FASEB J 18: 1788-1790.

Banks WA, Kastin AJ, Gutierrez EG (1994). Penetration of interleukin- 6 across the murine blood-brain barrier. Neurosci Lett 179: 53-56.

Benowitz LI, Routtenberg A (1997). GAP-43: an intrinsic determinant of neuronal development and plasticity. Trends Neurosci 20: 84-91.

Boisse L, Mouihate A, Ellis S, Pittman QJ (2004). Long-term alterations in neuroimmune responses after neonatal exposure to lipopolysaccharide. J Neurosci 24: 4928-4934.

Borrell J, Vela JM, Arevalo-Martin A, Molina-Holgado E, Guaza C (2002). Prenatal immune challenge disrupts sensorimotor gating in adult rats. Implications for the etiopathogenesis of schizophrenia. Neuropsychopharmacology 26: 204-215.

Braff D, Stone C, Callaway E, Geyer M, Glick I, Bali L (1978). Prestimulus effects on human startle reflex in normals and schizophrenics. Psychophysiology 15: 339-343.

Brown AS (2006). Prenatal infection as a risk factor for schizophrenia. Schizophr Bull 32: 200-202.

Brown AS, Begg MD, Gravenstein S, Schaefer CA, Wyatt RJ, Bresnahan M et al (2004a). Serologic evidence of prenatal influenza in the etiology of schizophrenia. Arch Gen Psychiatry 61: 774-780.

Brown AS, Hooton J, Schaefer CA, Zhang H, Petkova E, Babulas V et al (2004b). Elevated maternal interleukin-8 levels and risk of schizophrenia in adult offspring. Am J Psychiatry 161: 889-895.

Brown AS, Susser ES (2002). In utero infection and adult schizophrenia. Ment Retard Dev Disabil Res Rev 8: 51-57. 
Buka SL, Tsuang MT, Torrey EF, Klebanoff MA, Bernstein D, Yolken RH (2001). Maternal infections and subsequent psychosis among offspring. Arch Gen Psychiatry 58: 1032-1037.

Campeau S, Davis M (1995). Prepulse inhibition of the acoustic startle reflex using visual and auditory prepulses: disruption by apomorphine. Psychopharmacology (Berlin) 117: 267-274.

Chambers JS, Thomas D, Saland L, Neve RL, Perrone-Bizzozero NI (2005). Growth-associated protein 43 (GAP-43) and synaptophysin alterations in the dentate gyrus of patients with schizophrenia. Prog Neuropsychopharmacol Biol Psychiatry 29: 283-290.

Deutch AY (1992). The regulation of subcortical dopamine systems by the prefrontal cortex: interactions of central dopamine systems and the pathogenesis of schizophrenia. J Neural Transm Suppl 36: 61-89.

Drzyzga L, Obuchowicz E, Marcinowska A, Herman ZS (2006). Cytokines in schizophrenia and the effects of antipsychotic drugs. Brain Behav Immun 20: 532-545.

Eastwood SL (2004). The synaptic pathology of schizophrenia: is aberrant neurodevelopment and plasticity to blame? Int Rev Neurobiol 59: 47-72.

Ellenbroek BA, van den Kroonenberg PT, Cools AR (1998). The effects of an early stressful life event on sensorimotor gating in adult rats. Schizophr Res 30: 251-260.

Evans GJ, Cousin MA (2005). Tyrosine phosphorylation of synaptophysin in synaptic vesicle recycling. Biochem Soc Trans 33: $1350-1353$.

Fatemi SH, Sidwell R, Kist D, Akhter P, Meltzer HY, Bailey K et al (1998). Differential expression of synaptosome-associated protein $25 \mathrm{kDa}$ [SNAP-25] in hippocampi of neonatal mice following exposure to human influenza virus in utero. Brain Res 800: 1-9.

Fienberg AA, Hiroi N, Mermelstein PG, Song W, Snyder GL, Nishi A et al (1998). DARPP-32: regulator of the efficacy of dopaminergic neurotransmission. Science 281: 838-842.

Fortier ME, Joober R, Luheshi GN, Boksa P (2004). Maternal exposure to bacterial endotoxin during pregnancy enhances amphetamine-induced locomotion and startle responses in adult rat offspring. J Psychiatr Res 38: 335-345.

Gadient RA, Otten U (1994). Expression of interleukin-6 (IL-6) and interleukin-6 receptor (IL-6R) mRNAs in rat brain during postnatal development. Brain Res 637: 10-14.

Gayle DA, Beloosesky R, Desai M, Amidi F, Nunez SE, Ross MG (2004). Maternal LPS induces cytokines in the amniotic fluid and corticotropin releasing hormone in the fetal rat brain. Am J Physiol Regulintegr Comp Physiol 286: R1024-R1029.

Geyer MA, Krebs-Thomson K, Braff DL, Swerdlow NR (2001). Pharmacological studies of prepulse inhibition models of sensorimotor gating deficits in schizophrenia: a decade in review. Psychopharmacology (Berlin) 156: 117-154.

Gilmore JH, Fredrik JL, Vadlamudi S, Lauder JM (2004). Prenatal infection and risk for schizophrenia: IL-1beta, IL-6, and TNFalpha inhibit cortical neuron dendrite development. Neuropsychopharmacology 29: 1221-1229.

Gilmore JH, Jarskog LF, Vadlamudi S (2003). Maternal infection regulates BDNF and NGF expression in fetal and neonatal brain and maternal-fetal unit of the rat. J Neuroimmunol 138: 49-55.

Gilmore JH, Jarskog LF, Vadlamudi S (2005). Maternal poly I:C exposure during pregnancy regulates TNF alpha, BDNF, and NGF expression in neonatal brain and the maternal-fetal unit of the rat. J Neuroimmunol 159: 106-112.

Golan H, Levav T, Huleihel M (2004). Distinct expression and distribution of vesicular proteins in the hippocampus of TNFadeficient mice during development. Synapse 53: 6-10.

Golan HM, Lev V, Hallak M, Sorokin Y, Huleihel M (2005). Specific neurodevelopmental damage in mice offspring following maternal inflammation during pregnancy. Neuropharmacology 48: 903-917.
Graham FK (1975). Presidential address, 1974. The more or less startling effects of weak prestimulation. Psychophysiology 12: 238-248.

Gutierrez EG, Banks WA, Kastin AJ (1993). Murine tumor necrosis factor alpha is transported from blood to brain in the mouse. J Neuroimmunol 47: 169-176.

Halim ND, Weickert CS, McClintock BW, Hyde TM, Weinberger DR, Kleinman JE et al (2003). Presynaptic proteins in the prefrontal cortex of patients with schizophrenia and rats with abnormal prefrontal development. Mol Psychiatry 8: 797-810.

Hazlett EA, Buchsbaum MS, Haznedar MM, Singer MB, Germans MK, Schnur DB et al (1998). Prefrontal cortex glucose metabolism and startle eyeblink modification abnormalities in unmedicated schizophrenia patients. Psychophysiology 35: 186-198.

Hodgson DM, Knott B, Walker FR (2001). Neonatal endotoxin exposure influences HPA responsivity and impairs tumor immunity in Fischer 344 rats in adulthood. Pediatr Res 50: $750-755$.

Honer WG (1999). Assessing the machinery of mind: synapses in neuropsychiatric disorders. J Psychiatry Neurosci 24: 116-121.

Hornig M, Weissenbock H, Horscroft N, Lipkin WI (1999). An infection-based model of neurodevelopmental damage. Proc Natl Acad Sci USA 96: 12102-12107.

Humby T, Wilkinson LS, Robbins TW, Geyer MA (1996). Prepulses inhibit startle-induced reductions of extracellular dopamine in the nucleus accumbens of rat. J Neurosci 16: 2149-2156.

Jankowsky JL, Derrick BE, Patterson PH (2000). Cytokine responses to LTP induction in the rat hippocampus: a comparison of in vitro and in vivo techniques. Learn Mem 7: 400-412.

Jarskog LF, Xiao H, Wilkie MB, Lauder JM, Gilmore JH (1997). Cytokine regulation of embryonic rat dopamine and serotonin neuronal survival in vitro. Int J Dev Neurosci 15: 711-716.

Karson CN, Mrak RE, Schluterman KO, Sturner WQ, Sheng JG, Griffin WS (1999). Alterations in synaptic proteins and their encoding mRNAs in prefrontal cortex in schizophrenia: a possible neurochemical basis for 'hypofrontality'. Mol Psychiatry 4: 39-45.

Kim YK, Myint AM, Lee BH, Han CS, Lee HJ, Kim DJ et al (2004). Th1, Th2 and Th3 cytokine alteration in schizophrenia. Prog Neuropsychopharmacol Biol Psychiatry 28: 1129-1134.

Kobayashi R, Sekino Y, Shirao T, Tanaka S, Ogura T, Inada K et al (2004). Antisense knockdown of drebrin A, a dendritic spine protein, causes stronger preference, impaired pre-pulse inhibition, and an increased sensitivity to psychostimulant. Neurosci Res 49: 205-217.

Kowalski J, Blada P, Kucia K, Madej A, Herman ZS (2001). Neuroleptics normalize increased release of interleukin-1 beta and tumor necrosis factor-alpha from monocytes in schizophrenia. Schizophr Res 50: 169-175.

Kumari V, Soni W, Sharma T (1999). Normalization of information processing deficits in schizophrenia with clozapine. Am J Psychiatry 156: 1046-1051.

Lewis DA, Levitt P (2002). Schizophrenia as a disorder of neurodevelopment. Annu Rev Neurosci 25: 409-432.

Lewis DA, Lieberman JA (2000). Catching up on schizophrenia: natural history and neurobiology. Neuron 28: 325-334.

Licinio J, Seibyl JP, Altemus M, Charney DS, Krystal JH (1993). Elevated CSF levels of interleukin-2 in neuroleptic-free schizophrenic patients. Am J Psychiatry 150: 1408-1410.

Lipska BK (2004). Using animal models to test a neurodevelopmental hypothesis of schizophrenia. J Psychiatry Neurosci 29: 282-286.

McAllister CG, van Kammen DP, Rehn TJ, Miller AL, Gurklis J, Kelley ME et al (1995). Increases in CSF levels of interleukin-2 in schizophrenia: effects of recurrence of psychosis and medication status. Am J Psychiatry 152: 1291-1297. 
Mednick SA, Machon RA, Huttunen MO, Bonett D (1988). Adult schizophrenia following prenatal exposure to an influenza epidemic. Arch Gen Psychiatry 45: 189-192.

Meyer U, Nyffeler M, Engler A, Urwyler A, Schedlowski M, Knuesel I et al (2006). The time of prenatal immune challenge determines the specificity of inflammation-mediated brain and behavioral pathology. J Neurosci 26: 4752-4762.

Mirnics K, Levitt P, Lewis DA (2006). Critical appraisal of DNA microarrays in psychiatric genomics. Biol Psychiatry 60: 163-176.

Monteleone P, Fabrazzo M, Tortorella A, Maj M (1997). Plasma levels of interleukin-6 and tumor necrosis factor alpha in chronic schizophrenia: effects of clozapine treatment. Psychiatry Res 71: 11-17.

Nawa H, Takei N (2006). Recent progress in animal modeling of immune inflammatory processes in schizophrenia: implication of specific cytokines. Neurosci Res 56: 2-13.

Nemni R, Iannaccone S, Quattrini A, Smirne S, Sessa M, Lodi M et al (1992). Effect of chronic treatment with recombinant interleukin-2 on the central nervous system of adult and old mice. Brain Res 591: 248-252.

O'Callaghan E, Sham PC, Takei N, Murray G, Glover G, Hare EH et al (1994). The relationship of schizophrenic births to 16 infectious diseases. Br J Psychiatry 165: 353-356.

Pae CU, Yoon CH, Kim TS, Kim JJ, Park SH, Lee CU et al (2006). Antipsychotic treatment may alter T-helper (TH) 2 arm cytokines. Int Immunopharmacol 6: 666-671.

Park HJ, Won CK, Pyun KH, Shin HC (1995). Interleukin 2 suppresses afferent sensory transmission in the primary somatosensory cortex. Neuroreport 6: 1018-1020.

Paxinos G, Watson C (1997). The Rat Brain In Stereotaxic Coordinates, Compact 3rd edn. Academic: San Diego, London.

Quan N, Stern EL, Whiteside MB, Herkenham M (1999). Induction of pro-inflammatory cytokine mRNAs in the brain after peripheral injection of subseptic doses of lipopolysaccharide in the rat. J Neuroimmunol 93: 72-80.

Rapoport JL, Addington AM, Frangou S, Psych MR (2005). The neurodevelopmental model of schizophrenia: update 2005. Mol Psychiatry 10: 434-449.

Samuelsson AM, Jennische E, Hansson HA, Holmang A (2006). Prenatal exposure to interleukin-6 results in inflammatory neurodegeneration in hippocampus with $\mathrm{NMDA} / G A B A(A)$ dysregulation and impaired spatial learning. Am J Physiol Regul Integr Comp Physiol 290: R1345-R1356.

Schobitz B, de Kloet ER, Sutanto W, Holsboer F (1993). Cellular localization of interleukin $6 \mathrm{mRNA}$ and interleukin 6 receptor mRNA in rat brain. Eur J Neurosci 5: 1426-1435.

Schwabe K, Koch M (2004). Role of the medial prefrontal cortex in $\mathrm{N}$-methyl-D-aspartate receptor antagonist induced sensorimotor gating deficit in rats. Neurosci Lett 355: 5-8.

See RE, Ellison G (1990). Comparison of chronic administration of haloperidol and the atypical neuroleptics, clozapine and raclopride, in an animal model of tardive dyskinesia. Eur $J$ Pharmacol 181: 175-186.

Shanks N, Windle RJ, Perks PA, Harbuz MS, Jessop DS, Ingram CD et al (2000). Early-life exposure to endotoxin alters hypothalamic-pituitary-adrenal function and predisposition to inflammation. Proc Natl Acad Sci USA 97: 5645-5650.

Shi L, Fatemi SH, Sidwell RW, Patterson PH (2003). Maternal influenza infection causes marked behavioral and pharmacological changes in the offspring. J Neurosci 23: 297-302.

Snyder GL, Fienberg AA, Huganir RL, Greengard P (1998). A dopamine/D1 receptor/protein kinase A/dopamine- and cAMPregulated phosphoprotein $(\mathrm{Mr} 32 \mathrm{kDa}) /$ protein phosphatase-1 pathway regulates dephosphorylation of the NMDA receptor. J Neurosci 18: 10297-10303.
Suvisaari J, Haukka J, Tanskanen A, Hovi T, Lonnqvist J (1999). Association between prenatal exposure to poliovirus infection and adult schizophrenia. Am J Psychiatry 156: 1100-1102.

Swerdlow NR, Braff DL, Geyer MA, Koob GF (1986). Central dopamine hyperactivity in rats mimics abnormal acoustic startle response in schizophrenics. Biol Psychiatry 21: 23-33.

Swerdlow NR, Geyer MA (1998). Using an animal model of deficient sensorimotor gating to study the pathophysiology and new treatments of schizophrenia. Schizophr Bull 24: 285-301.

Swerdlow NR, Koob GF (1987). Lesions of the dorsomedial nucleus of the thalamus, medial prefrontal cortex and pedunculopontine nucleus: effects on locomotor activity mediated by nucleus accumbens-ventral pallidal circuitry. Brain Res 412: 233-243.

Swerdlow NR, Talledo J, Sutherland AN, Nagy D, Shoemaker JM (2006). Antipsychotic effects on prepulse inhibition in normal 'low gating' humans and rats. Neuropsychopharmacology 31: 2011-2021.

Tancredi V, Zona C, Velotti F, Eusebi F, Santoni A (1990). Interleukin-2 suppresses established long-term potentiation and inhibits its induction in the rat hippocampus. Brain Res 525: 149-151.

Thompson PM, Egbufoama S, Vawter MP (2003). SNAP-25 reduction in the hippocampus of patients with schizophrenia. Prog Neuropsychopharmacol Biol Psychiatry 27: 411-417.

Tohmi M, Tsuda N, Watanabe Y, Kakita A, Nawa H (2004). Perinatal inflammatory cytokine challenge results in distinct neurobehavioral alterations in rats: implication in psychiatric disorders of developmental origin. Neurosci Res 50: 67-75.

Urakubo A, Jarskog LF, Lieberman JA, Gilmore JH (2001). Prenatal exposure to maternal infection alters cytokine expression in the placenta, amniotic fluid, and fetal brain. Schizophr Res 47: 27-36.

Waguespack PJ, Banks WA, Kastin AJ (1994). Interleukin-2 does not cross the blood-brain barrier by a saturable transport system. Brain Res Bull 34: 103-109.

Watanabe Y, Hashimoto S, Kakita A, Takahashi H, Ko J, Mizuno M et al (2004). Neonatal impact of leukemia inhibitory factor on neurobehavioral development in rats. Neurosci Res 48: 345-353.

Weike AI, Bauer U, Hamm AO (2000). Effective neuroleptic medication removes prepulse inhibition deficits in schizophrenia patients. Biol Psychiatry 47: 61-70.

Wiedenmann B, Franke WW (1985). Identification and localization of synaptophysin, an integral membrane glycoprotein of $\mathrm{Mr}$ 38000 characteristic of presynaptic vesicles. Cell 41: 1017-1028.

Wright SD, Ramos RA, Tobias PS, Ulevitch RJ, Mathison JC (1990). CD14, a receptor for complexes of lipopolysaccharide (LPS) and LPS binding protein. Science 249: 1431-1433.

Yang L, Lindholm K, Konishi Y, Li R, Shen Y (2002). Target depletion of distinct tumor necrosis factor receptor subtypes reveals hippocampal neuron death and survival through different signal transduction pathways. J Neurosci 22: 3025-3032.

Yolken RH, Karlsson H, Yee F, Johnston-Wilson NL, Torrey EF (2000). Endogenous retroviruses and schizophrenia. Brain Res Brain Res Rev 31: 193-199.

Zalcman SS (2002). Interleukin-2-induced increases in climbing behavior: inhibition by dopamine D-1 and D-2 receptor antagonists. Brain Res 944: 157-164.

Zorrilla EP (1997). Multiparous species present problems (and possibilities) to developmentalists. Dev Psychobiol 30: 141-150.

Zuckerman L, Rehavi M, Nachman R, Weiner I (2003). Immune activation during pregnancy in rats leads to a postpubertal emergence of disrupted latent inhibition, dopaminergic hyperfunction, and altered limbic morphology in the offspring: a novel neurodevelopmental model of schizophrenia. Neuropsychopharmacology 28: 1778-1789. 